\title{
Efficiency Evaluation of Main Ports of the Yangtze River Main Line-Empirical Research Based on Three-Stage DEA Model
}

\author{
Jianbao Zhang, Linan Du * \\ China Waterborne Transport Research Institute, Beijing 100088, China \\ * linandu2000@126.com
}

\begin{abstract}
Port efficiency evaluation has always been a hot issue in transportation economy and shipping economy research. This paper attempts to evaluate the efficiency of main ports of the Yangtze River main line by using three-stage DEA model, reveals the efficiency change trend and spatial characteristics of ports of the Yangtze River main line, and then proposes policy suggestions for improving port efficiency, the research conclusion has certain reference value for promoting the port development of the Yangtze River main line, and better support the construction of the Yangtze River economic belt.
\end{abstract}

Keywords: DEA; Yangtze River main line; port development; economic belt.

\section{Research Methods}

Data envelopment analysis (DEA) was initially proposed by Charnes, Cooper, and Rhode in 1978, but this model did not consider the impact of environmental variables and random errors on the evaluation results, resulting in lower accuracy of evaluation results. Fried $(1999,2002)$ explores how environmental factors and random noise can be introduced into the DEA model, which is called as the three-stage DEA model.

\subsection{The First Stage: Traditional DEA Model}

In the first stage, the original input-output data is used to construct an input-oriented BCC (variable return to scale) model for initial efficiency evaluation. The DEA model is essentially a linear programming problem. For any decision-making unit, the input-directed dual-form BCC model can be expressed as:

$$
\text { s.t. }\left\{\begin{array}{l}
\min \theta-\varepsilon\left(\hat{e}^{T} S^{-}+e^{T} S^{+}\right) \\
\sum_{j=1}^{n} X_{j} \lambda_{j}+S^{-}=\theta X_{0} \\
\sum_{j=1}^{n} Y_{j} \lambda_{j}-S^{+}=Y_{0} \\
\lambda_{j} \geq 0, S^{-}, S^{+} \geq 0
\end{array}\right.
$$

Among them, $j=1,2, \cdots, n$ represents decision-making unit, $X, Y$ are input and output vector, respectively.

If $\theta=1, S^{+}=S^{-}=0$, then the decision-making unit DEA is effective;

If $\theta=1, S^{+} \neq 0$, or $S^{-} \neq 0$, then the decision-making unit weak DEA is effective;

If $\theta<1$, and then the decision-making unit is not effective for DEA.

The efficiency value calculated by the BCC model is the comprehensive technical efficiency (TE), which can be further divided into scale efficiency (SE) and pure technical efficiency (PTE), TE=SE* PTE.

\subsection{The Second Stage: SFA Model}

In the second stage, focusing on investing in the output slack variable $[x-X \lambda]$, it can reflect the initial inefficiency, it consists of environmental factors, management inefficiency and statistical noise, regression analysis are carried out for environmental variables by constructing SFA model, the effects of the above three factors can be observed respectively. 
(1) Construct slack variables

$$
S_{n i}=x_{n i}-x_{n i} \times \lambda, n=1, \ldots, N ; i=1,2, \ldots, I
$$

Among them, $x_{n i}$ is the $\mathrm{n}$-th input value of $\mathrm{i}$-th decision-making unit (DMU), $x_{n i} \times \lambda$ is the optimal mapping of the nth input value of efficiency frontier surface of the $n$-th input value of $i$-th DMU, and $S_{n i}$ represents the corresponding input slack variable.

(2) Construct the SFA regression function model

$$
S_{n i}=f\left(Z_{i} ; \beta_{n}\right)+v_{n i}+\mu_{n i} ; i=1,2, \cdots, I ; n=1,2, \cdots, N
$$

Among them, $S_{n i}$ is the slack value of $n$ input of $i$ decision-making unit, $Z_{i}$ is the environmental variable, $\beta_{n}$ is the coefficient of the environmental variable; $v_{n i}+\mu_{n i}$ is the mixed error term, $v_{n i}$ represents random disturbance, $\mu_{n i}$ represents management inefficiency. Among them, $v \sim N\left(0, \sigma_{v}{ }^{2}\right)$ is the random error term, which represents the impact of random disturbance factors on the input slack variables; $\mu$ is the management inefficiency, which represents the influence of management factors on the input slack variables, assuming that it obeys the normal distribution in zero point truncation, namely $\mu \sim N^{+}\left(0, \sigma_{\mu}{ }^{2}\right)$.

(3) Adjust the input variable

The purpose of SFA regression is to eliminate the effects of environmental and random factors on efficiency measures, so adjust all decision-making units to the same external environment. The adjustment formula is as follows:

$$
X_{n i}^{A}=X_{n i}+\left[\max \left(f\left(Z_{i} ; \hat{\beta}_{n}\right)\right)-f\left(Z_{i} ; \hat{\beta}_{n}\right)\right]+\left[\max \left(v_{n i}\right)-v_{n i}\right] \quad i=1,2, \cdots, I ; n=1,2, \cdots, N
$$

Among them, $X_{n i}^{A}$ is the input after adjustment; $X_{n i}$ is the input before adjustment; $\left[\max \left(f\left(Z_{i} ; \hat{\beta}_{n}\right)\right)-f\left(Z_{i} ; \hat{\beta}_{n}\right)\right]$ is to adjust the external environmental factors; $\left[\max \left(v_{n i}\right)-v_{n i}\right]$ is to put all decision-making units under the same luck level.

\subsection{The Third Stage: DEA Model after Adjustment}

In the third stage, the DEA model after adjustment is constructed, namely the values of the input variables adjusted in the second stage are re-substituted into the BCC model of the first stage, and the DMU efficiency after deducted the environmental variables and the random error terms is calculated. The efficiency value obtained by this method excludes the influence of the operating environment and statistical noise, and it is more objectively and truly reflects the actual efficiency.

The calculation tools used in this paper are DEAP2.1 and FRONTIER4.1 software.

\section{Selection of Evaluation Indicators}

\subsection{Input and Output Indicators}

This paper mainly considers the shoreline and land resources, facilities and equipment, and construction investment in the selection of input indicators, considering availability of data and rationality of indicators, the specific selection indicators include the length of quay berth, the warehouse area for production, storage yard area, the number of loading and unloading machinery and the investment in port and shipping construction, the input indicators are mainly measured from capital, labor and land. Output indicators select the most widely used cargo throughput and container throughput. 


\subsection{Environmental Variable}

From port development progress, port efficiency is not only affected by the above input and output variables, but also influenced by environmental factors such as foreign trade, economic development in the hinterland, and macroeconomic policies. Environmental variables refer to factors that affect port efficiency but without the subjective controllable range of the samples. Therefore, this paper mainly considers the following two factors as environmental variables: (1) per capita GDP, it comprehensively reflects the economic development level of a region, it is not only a demand factor for port development, but also affects supply from port construction; (2) value of foreign trade, it mainly reflects the demand of the port, in the cargo throughput of the port, the foreign trade throughput occupies a considerable proportion, under the same input level, the foreign trade volume will have an impact on the output.

\subsection{Research Samples and Data Sources}

This paper takes 20 major ports of the Yangtze River mainline as research samples, including upstream (Yichang Port, Chongqing Port, Luzhou Port and Yibin Port), Midstream (Wuhan Port, Huangshi Port, Jingzhou Port, Jiujiang Port) and downstream (Nanjing Port, Zhenjiang Port, Suzhou Port, Nantong Port, Jiangyin Port, Yangzhou Port, Taizhou Port, Maanshan Port, Wuhu Port, Tongling Port, Chizhou Port, Anqing Port).

The port input and output indicators used in this paper are derived from the 2016 "National Traffic Statistical Data Collection", the port's construction investment comes from the "China Port Yearbook", the environmental factor indicators are derived from the "China City Statistical Yearbook", and the "Statistical Bulletin on National Economic and Social Development" in various port cities.

\section{Empirical Analysis}

\subsection{The First Stage: Analysis Results of Traditional DEA Model}

In the first stage, DEAP2.1 was used to analyze the efficiency level and returns to scale of 20 main ports on the Yangtze River, the results are shown in Table 1. It can be seen that when does not consider environmental variables and random factors, the average overall efficiency in 2016 is 0.887 , the average pure technical efficiency is 0.941 , and the average scale efficiency is 0.941 , in general, the overall efficiency of ports the Yangtze River main line is higher.

(1) The efficiency gap among the ports of the Yangtze River main line is obvious from the comparison of ports. In 2016, comprehensive efficiency of more than half of the 20 main ports was 1 and achieved efficiency frontiers. However, the pure technical efficiency of Nantong Port, Yangzhou Port and Jingzhou Port are all 1, the decrease of comprehensive efficiency level is due to the decrease of scale efficiency, and it shows that the three ports themselves do not have the phenomenon of input redundancy and output insufficiency, but there is inefficiency caused by the mismatch between scale and input and output, it is necessary to further optimize the port scale to achieve higher economic benefits. However, the comprehensive efficiency of Chongqing Port has not reached an effective frontier, and it is mainly due to low scale efficiency, redundant input and insufficient output, the input factors should be adjusted according to specific conditions, and the construction of deep-water wharf and berths should be encouraged, improve shipping capacity and perfect the evacuation and distribution system, optimize the input-output structure and improve the efficiency of port operation.

(2) From returns to scale, in 2016, most ports were represented as ports with the changeless returns to scale, which means that increasing various input factors in the same proportion can only bring about the same proportion of output increase, and the port reaches the efficiency frontier. Among the ports that did not reach the efficiency frontier, Nantong Port, Jiujiang Port and Chongqing Port showed diminishing returns to scale, other ports showed increasing returns to scale, namely increasing their input indicators could lead to more efficient output. In addition, except for Chizhou Port, other ports' technical efficiency is lower than their comprehensive efficiency, namely inefficiency mainly 
comes from technical inefficiency, but does not exclude the influence of objective environment and random factors.

(3) From the analysis of efficiency agent, scale efficiency is lower than pure technical efficiency, which prevails in most ports, and the scale efficiency is lower, due to the strong scale economy in the port industry, small initial scale, scattered investment, and the business of ports and upstream and downstream enterprises is difficult to connect with each other, there is no integrated business development model, it is difficult to form scale effect, while the relatively high pure technology efficiency is subject to the rapid development of regional economy and foreign trade, port cargo throughput and container throughput continue to increase, and the established investment in port resources has produced high economic benefit.

Table 1. efficiency evaluation and comparison of the port of the Yangtze River main line in 2016

\begin{tabular}{|c|c|c|c|c|c|}
\hline Firm & Port & crste & vrste & scale & Scale reward \\
\hline 1 & Nanjing & 1.000 & 1.000 & 1.000 & - \\
\hline 2 & Zhenjiang & 1.000 & 1.000 & 1.000 & - \\
\hline 3 & Suzhou & 1.000 & 1.000 & 1.000 & - \\
\hline 4 & Nantong & 0.894 & 1.000 & 0.894 & drs \\
\hline 5 & Jiangyin & 1.000 & 1.000 & 1.000 & - \\
\hline 6 & Yangzhou & 0.794 & 1.000 & 0.794 & irs \\
\hline 7 & Taizhou & 1.000 & 1.000 & 1.000 & - \\
\hline 8 & Maanshan & 0.833 & 0.841 & 0.990 & irs \\
\hline 9 & Wuhu & 1.000 & 1.000 & 1.000 & - \\
\hline 10 & Tongling & 1.000 & 1.000 & 1.000 & - \\
\hline 11 & Chizhou & 0.706 & 0.865 & 0.817 & irs \\
\hline 12 & Anqing & 1.000 & 1.000 & 1.000 & - \\
\hline 13 & Jiujiang & 0.862 & 0.881 & 0.979 & drs \\
\hline 14 & Wuhan & 0.536 & 0.569 & 0.943 & irs \\
\hline 15 & Huangshi & 1.000 & 1.000 & 1.000 & - \\
\hline 16 & Jingzhou & 0.575 & 1.000 & 0.575 & irs \\
\hline 17 & Yichang & 1.000 & 1.000 & 1.000 & - \\
\hline 18 & Chongqing & 0.544 & 0.655 & 0.830 & drs \\
\hline 19 & Luzhou & 1.000 & 1.000 & 1.000 & - \\
\hline 20 & Yibin & 1.000 & 1.000 & 1.000 & - \\
\hline \multicolumn{2}{|c|}{ mean value } & 0.887 & 0.941 & 0.941 & \\
\hline
\end{tabular}

Note: IRS indicates increasing returns to scale. DRS means diminishing returns to scale.

\subsection{The Second Stage: Similar to SFA Regression Analysis Results}

In the second stage, FRONTIER4.1 is used to take the slack variables of the five input variables of DEA analysis results in the first stage are as the explanatory variables, and per capita GDP and value of foreign trade two environmental variables selected above are used as explanatory variables to construct SFA regression model, since input slack variable as regression, therefore, the coefficient is negative, which shows the favorable factors for input slack variables. The result is shown in table.2.

According to the regression results in Table 2 above, it can be seen that the per capita GDP and value of foreign trade of the port have passed the test at least $10 \%$ significance level, it shows the increase of economic development level and value of foreign trade in the hinterland, it plays a positive guiding role in the development of the port economy, it is conducive to improve the port input-output ratio and can significantly affect the port economy efficiency. 
Table 2. regression analysis results of the input slack variables of ports of the Yangtze River main line in 2016

\begin{tabular}{cccccc}
\hline \multirow{2}{*}{ Index } & $\begin{array}{c}\text { berth } \\
\text { length, }\end{array}$ & $\begin{array}{c}\text { warehouse } \\
\text { area }\end{array}$ & yard area & $\begin{array}{c}\text { machinery } \\
\text { quantity }\end{array}$ & $\begin{array}{c}\text { construction } \\
\text { investmen }\end{array}$ \\
\hline \multirow{2}{*}{ Constant } & -5825.43 & -61189.31 & -532420.40 & -418.39 & -6.56 \\
& $(1.00)$ & $(1.00)$ & $(1.00)$ & $(1.0016)$ & $(1.0953)$ \\
Per capita GDP & $0.0329^{*}$ & $0.0614^{*}$ & $-2.2404^{*}$ & $0.0022^{*}$ & $0.0000^{*}$ \\
& $(0.0367)$ & $(0.1289)$ & $(3.6550)$ & $(0.0004)$ & $(0.00)$ \\
Foreign trade volume & $-1.9429^{*}$ & $19.1605^{*}$ & $314.8061^{*}$ & $0.0353^{*}$ & $-0.0005^{*}$ \\
& $(3.2024)$ & $(0.9997)$ & $(0.9995)$ & $(0.2906)$ & $(0.0019)$ \\
$\sigma^{2}$ & $2.54 \mathrm{E}+08$ & $4.99 \mathrm{E}+10$ & $1.71 \mathrm{E}+12$ & $5.78 \mathrm{E}+05$ & $1.02 \mathrm{E}+02$ \\
& $(1.00)$ & $(1.00)$ & $(1.00)$ & $(1.00)$ & $(1.0014)$ \\
$\gamma$ & 1.00 & 1.00 & 1.00 & 1.00 & 1.00 \\
$\log$ likelihood function & $(0.0002)$ & $(0.00)$ & $(0.0001)$ & $(0.00)$ & $(0.00)$ \\
LR test of the one-sided error & -204.53 & -257.67 & -294.87 & -144.61 & -58.64 \\
\hline
\end{tabular}

Note: * indicates a significant level of at least $10 \%$; standard deviation in brackets.

(1) Per capita GDP. The per capita GDP is unfavorable factor to length of quay berth, the warehouse area, and the number of loading and unloading machinery, it may be increased greatly due to the increase of per capita GDP and investment of inland port, but it has not brought about a proportional increase of port throughput, thus resulting in waste of port resources. However, it is a favorable factor for the slack variable of the storage yard area, the increase of per capita GDP maybe leads to increase of cargo throughput, thereby increasing port investment utilization. In addition, the impact of per capita GDP on investment in port and shipping construction is not obvious.

(2) Value of foreign trade. The value of foreign trade is a favorable factor for length of quay berth and investment in port and shipping construction. The increase of value of foreign trade maybe brings increase of port cargo throughput, thereby driving the construction of infrastructure such as wharf and channel, and further promotes the input-output efficiency of ports. However, this indicator is unfavorable factor to the warehouse area, storage yard and the number of loading and unloading machinery, the increase of value of foreign trade maybe brings increase of investment in fixed assets of the port, but the output has not increased accordingly, resulting in lower resource utilization of ports.

The above shows that the operational efficiency of China's ports is significantly affected by environmental variables and random factors, if the effects of random factors and environmental variables are not removed; it is likely that efficiency assessment errors will occur. Therefore, based on the regression results at this stage, this paper re-adjusts the port input variables, keeps the original output variables unchanged, and uses Deap2.1 software again, and obtain the true efficiency values of the ports that are affected by the environment and random variables.

\subsection{The Third Stage: Empirical Analysis of DEA after Input Adjustment}

According to the adjusted input variables of the second stage, the traditional DEA-BCC model is used again to analyze the main port efficiency of the Yangtze River main line in 2016, and the final efficiency values of each port are shown in Table 3.

By comparing the DEA results of the third stage and the first stage, namely compare Tables 1 and 3 , it can be seen that the efficiency of the decision-making unit is significantly different after the effects of environmental and random variables are eliminated. Specifically:

(1) Comparison of the average efficiency of the two stages. The pure technical efficiency and scale efficiency of the main ports of the Yangtze River main line are greatly affected by environmental variables and random factors, under the same conditions, the comprehensive efficiency values and scale efficiency values of each port showed a downward trend in 2016, and the pure technical efficiency showed an upward trend. It can be seen that the reduction of scale efficiency is the main 
reason affecting the decline of the comprehensive efficiency values, it shows that the port investment structure and scale do not match, and it is necessary to optimize the port scale according to the increase and decrease conditions of returns to scale of the different ports, and further improve the port efficiency.

Table 3. Efficiency evaluation and comparison of ports the Yangtze River main line under the same

\begin{tabular}{|c|c|c|c|c|c|}
\hline Firm & Port & crste & virste & & S \\
\hline 1 & Naniing & 1000 & 1000 & 1000 & \\
\hline & & & & & \\
\hline 2 & Zhenjiang & 1.000 & 1.000 & 1.000 & - \\
\hline 3 & Suzhou & 1.000 & 1.000 & 1.000 & - \\
\hline 4 & Nantong & 1.000 & 1.000 & 1.000 & - \\
\hline 5 & Jiangyin & 1.000 & 1.000 & 1.000 & - \\
\hline 6 & Yangzhou & 0.682 & 1.000 & 0.682 & irs \\
\hline 7 & Taizhou & 1.000 & 1.000 & 1.000 & - \\
\hline 8 & Maanshan & 0.845 & 0.897 & 0.941 & irs \\
\hline 9 & Wuhu & 1.000 & 1.000 & 1.000 & - \\
\hline 10 & Tongling & 1.000 & 1.000 & 1.000 & - \\
\hline 11 & Chizhou & 0.477 & 0.935 & 0.510 & irs \\
\hline 12 & Anqing & 0.319 & 1.000 & 0.319 & irs \\
\hline 13 & Jiujiang & 0.830 & 0.933 & 0.890 & irs \\
\hline 14 & Wuhan & 0.521 & 0.668 & 0.781 & irs \\
\hline 15 & Huangshi & 0.528 & 1.000 & 0.528 & irs \\
\hline 16 & Jingzhou & 0.172 & 1.000 & 0.172 & irs \\
\hline 17 & Yichang & 0.209 & 1.000 & 0.209 & irs \\
\hline 18 & Chongqing & 0.643 & 0.687 & 0.936 & irs \\
\hline 19 & Luzhou & 0.451 & 1.000 & 0.451 & irs \\
\hline 20 & Yibin & 0.502 & 1.000 & 0.502 & irs \\
\hline \multicolumn{2}{|c|}{ mean value } & 0.709 & 0.956 & 0.746 & \\
\hline
\end{tabular}

(2) Analysis of the pure technical efficiency of the port in two stages. In 2016, except the port that achieved the efficiency frontier, the net technical efficiency of all ports increased significantly, it shows that the matching of port input and output levels has increased significantly in recent years, and the input factor structure of all ports has brought greater output effect.

(3) Analysis of the scale efficiency of the port in two stages. In 2016, except the scale efficiency of Nantong Port improved, other ports showed a decline in scale efficiency, it shows that under the same environment, the scale does not match the its output, and it is necessary to adjust and optimize the port scale to make them conform to the current development of each port.

\section{Conclusion and Suggestions}

This paper uses the three-stage DEA model to compare and analyze the economic efficiency of the 20 main ports of the Yangtze River main line in 2016, the results show that: the main ports of the Yangtze River main line, especially the middle and upper reaches of the port, their scale efficiency is relatively low, investment is scattered, and it is difficult to form scale economy effect. Most of the ports on the Yangtze River main line have the best technical efficiency, and some ports still have the status of investment congestion and low output levels, and port resources are wasted. Random factors and environmental variables have a significant impact on the economic efficiency of the port, it is necessary to improve the economy efficiency of ports by controlling and grasping external environmental variables. Based on this, this paper proposes: 
(1) Optimizing the resources allocation of ports and strengthening cooperation among ports in the region. Accelerating the construction of Wuhan Yangtze River midstream shipping center, Chongqing Yangtze River upstream shipping center and Nanjing regional shipping logistics center, expanding the economic influence of the hinterland, strengthening cooperation between ports and hinterland enterprises, extending the port industry chains and promoting scale development.

(2) Strengthening port information construction and build smart port. By planning and improving port production management information, business information, logistics information, and electronic ports and the construction of other infrastructure platforms, port information resources and industries are further integrated, and facilitate clearance department, port, upstream and downstream enterprises, logistics enterprises to carry out business cooperation, relying on the Yangtze River golden waterway, promoting China's east, central and west three areas accord with the world market, and construct a market-oriented, digital, and international port service system.

(3) Vigorously promoting the development of multimodal transport in the Yangtze River economic belt. The shipping centers and main ports as the key points, accelerating the construction of connecting lines among railways, high-grade roads and important port areas, strengthening the service functions of collection and distribution, building networked comprehensive traffic corridors and several comprehensive transportation hubs based on multimodal transport, effectively reducing logistics costs, making multimodal transport truly become the development carrier of industrial transfer and business innovation, building a new pattern of opening up of the Yangtze River economic belt from east to west and combine land and sea, and promote high-quality economic and social development along the Yangtze River economic belt.

\section{References}

[1]. Gabriel Figueiredo De Oliveira, Pierre Cariou, 2015, “ The impact of competition on container port (in)efficiency", Transportation Research Part A, 78: 124-133.

[2]. Andrew Chi-lok Yuen, Anming Zhang, Waiman Cheung, 2013, “Foreign participation and competition: A way to improve the container port efficiency in China?", Transportation Research Part A, 49:220-231.

[3]. Wang Ling, Bi Zhiwen. Evaluating the Operational Efficiency of Major Inland Ports in China using the 3-Stage DEA Model [J]. Industrial Economics Research,2010,04:40-48.

[4]. Charnes, A. W., Cooper, W., Rhodes, E. ,1978, "Measuring the Efficiency of Decision-Making Units”, European Journal of Operational Research,2 (4): 429-444. 